\title{
Comunicação
}

[Communication $]$

\section{Comparação dos caldos selenito cistina, tetrationato Muller-Kauffmann e Rappaport- Vassiliadis no isolamento de Salmonella Typhimurium}

\author{
[Comparison of selenite cystine, tetrathionate Muller-Kauffmann and Rappaport-Vassiliadis broths \\ for Salmonella Typhimurium isolation] \\ L.G. Ávila ${ }^{1}$, D.G. Silva ${ }^{2}$, J.J. Fagliari ${ }^{3}$ \\ ${ }^{1}$ Aluna de pós-graduação - Faculdade de Medicina Veterinária de Araçatuba - Araçatuba, SP
${ }^{2}$ Pós-doutoranda - Faculdade de Ciências Agrárias e Veterinárias - UNESP- Jaboticabal, SP
${ }^{3}$ Faculdade de Ciências Agrárias e Veterinárias - UNESP- Jaboticabal, SP
}

A salmonelose bovina é uma enfermidade que vem se destacando pelo impacto econômico na pecuária e pelas implicações na área de saúde pública (Veling et al., 2002). Embora os bovinos possam ser infectados por diferentes sorotipos de Salmonella, a salmonelose bovina é causada principalmente pelos sorotipos $S$. dublin e $S$. Typhimurium (Santos et al., 2002a).

As etapas necessárias para o isolamento de espécimes do gênero Salmonella incluem préenriquecimento não seletivo, enriquecimento direto (seletivo), plaqueamento em meio semissólido e confirmação bioquímica e sorológica (Waltman, 2000).

Os caldos de enriquecimento seletivo mais comuns são os caldos selenito, tetrationato e Rappaport-Vassiliadis (Nascimento et al., 2000).

Entretanto, apesar de a literatura científica dispor de vários trabalhos sobre qual meio de enriquecimento seletivo é mais apropriado para o isolamento de Salmonella, os resultados são confusos e contraditórios.

Assim, o objetivo do presente estudo foi avaliar a eficiência dos caldos de enriquecimento seletivos, selenito cistina, tetrationato Muller-Kauffmann e Rappaport-Vassiliadis, no isolamento de Salmonella Typhimurium em amostras de fezes de bezerro experimentalmente infectado.

Recebido em 28 de setembro de 2010

Aceito em 2 de janeiro de 2012

E-mail: lgavila_10@hotmail.com
Foram analisadas 15 amostras de swabs retais de um bezerro macho da raça Holandesa, com aproximadamente 15 dias de idade, infectado experimentalmente com $10^{9}$ unidades formadoras de colônia (UFC) de Salmonella Typhimurium (Santos et al., 2002b). As amostras foram colhidas em triplicata, imediatamente antes da inoculação (M0) e a intervalos de 24 horas, ao longo de 14 dias após a infecção experimental (M1 a M14).

Para o isolamento de Salmonella Typhimurium, foram testados três caldos de enriquecimento seletivo: selenito cistina (SC), tetrationato Muller-Kauffmann (TMK) e RappaportVassiliadis (RV).

Das três amostras de swabs retais colhidas num mesmo momento, duas foram diretamente inoculadas em $10 \mathrm{~mL}$ de caldo SC (Oxoid CM0699) e TMK (Oxoid CM0343) e incubadas a $37^{\circ} \mathrm{C}$ durante 24 horas. A outra amostra foi inicialmente pré-enriquecida em $10 \mathrm{~mL}$ de caldo GN-Hajna (Difco 0486-17) e incubada a $37^{\circ} \mathrm{C}$ por 24 horas. Após o crescimento, transferiu-se $0,1 \mathrm{~mL}$ para um tubo contendo $9,9 \mathrm{~mL}$ de caldo RV (Oxoid CM0866), que foi incubado a $42^{\circ} \mathrm{C}$ durante 24 horas. Após incubação, os caldos foram semeados em placas contendo ágar verde brilhante modificado (Oxoid CM0329) e incubados a $37^{\circ} \mathrm{C}$ por 24 horas. De cada placa, três colônias sugestivas de bactérias do gênero Salmonella foram inoculadas em tubos contendo ágar tríplice açúcar e ferro (Oxoid CM0277) e ágar lisina ferro (Oxoid CM0381). Todas as 
colônias identificadas presuntivamente como Salmonella foram submetidas ao teste de soroaglutinação em lâmina, com soro polivalente antiantígenos somáticos $(\mathrm{O})$ e com soro polivalente antiantígenos flagelares (H) de Salmonella (Probac do Brasil).

Os resultados obtidos foram analisados estatisticamente pelo teste de McNemar (Zar, 1999).

As amostras colhidas antes da infecção experimental foram negativas para $S$. Typhimurium em todos os caldos avaliados.
Não foram encontradas diferenças significativas entre os resultados do isolamento de $S$. Typhimurium com a utilização dos três caldos de enriquecimento seletivo $(\mathrm{P}>0,05)$, entretanto os caldos SC e TMK apresentaram maior eficiência no isolamento de $S$. Typhimurium, com resultados idênticos (12 amostras positivas) (Tab. 1).

Estes resultados diferem daqueles descritos por Silva et al. (2008), Freschi et al. (2005) e Bager e Petersen (1991), que relataram superioridade do uso do caldo SC, TMK e RV, respectivamente, no isolamento de Salmonella spp a partir de amostras de fezes.

Tabela 1. Isolamento de Salmonella Typhimurium a partir de amostras de swabs retais de bezerro infectado experimentalmente com $10^{9}$ UFC de $S$. Typhimurium, utilizando-se os caldos de enriquecimento seletivo selenito cistina (SC), tetrationato Muller-Kauffmann (TMK) e RappaportVassiliadis (RV)

\begin{tabular}{ccccc}
\hline & & Caldos de enriquecimento seletivo & \\
\cline { 2 - 4 } Amostras & SC & TMK & RV \\
\hline M0 & - & - & - \\
M1 & + & + & + \\
M2 & + & + & + \\
M3 & + & + & + \\
M4 & + & + & + \\
M5 & + & + & + \\
M6 & + & + & - \\
M7 & + & + & + \\
M8 & + & + & + \\
M9 & + & + & + \\
M10 & + & + & + \\
M11 & + & + & + \\
M12 & + & - & - \\
M13 & - & - & - \\
M14 & - & 12 & - \\
Total & 12 & & 10
\end{tabular}

M: momento da colheita da amostra.

+: positivo para Salmonella Typhimurium; - : negativo para Salmonella Typhimurium.

O caldo RV apresentou desempenho inferior aos caldos SC e TMK, pois em dois momentos, M6 (144 horas após a inoculação de $S$. Typhimurium) e M12 (288 horas após a infecção experimental), houve resultado negativo (Tab. 1). A etapa de pré-enriquecimento no caldo GNHajna pode ter interferido negativamente no isolamento de $S$. Typhimurium por possibilitar o crescimento indiscriminado de outras enterobactérias presentes nas amostras de swabs retais.
Os resultados obtidos mostraram que os caldos SC e TMK foram as melhores opções de caldos de enriquecimento seletivo para o isolamento de Salmonella Typhimurium a partir de swabs retais de bezerro. Além disso, o caldo RV apresenta a necessidade de uma fase de pré-enriquecimento, retardando o tempo para o resultado do isolamento microbiológico.

Palavras-chave: bezerro, fezes, meio de enriquecimento seletivo, Salmonella Typhimurium 


\begin{abstract}
Three selective enrichment broths - selenite cystine (SC), Muller-Kauffmann tetrathionate (MKT) and Rappaport-Vassiliadis $(R V)$ - were compared, for Salmonella Typhimurium isolation from rectal swabs of a calf experimentally infected. The bacteriological procedure involved pre-enrichment in Hajna-GN broth (only for the samples inoculated in RV broth), selective enrichment (SC, MKT and RV broths), culture in modified brilliant green agar (BGA), presumptive biochemistry tests (using triple-sugar-iron agar and lysine-agar) and slide agglutination test with poli-O and poli-H Salmonella antisera. SC and MKT broths were more efficient in the isolation of Salmonella Typhimurium (12 positive samples), whereas $R V$ broth had a lower efficiency in the microbiological isolation (ten positive samples).
\end{abstract}

Keywords: calves, feces, selective enrichment broth, Salmonella typhimurium

\section{AGRADECIMENTOS}

Os autores agradecem à FAPESP pela concessão de bolsa de estudo e pelo auxílio financeiro, e à Fundação Oswaldo Cruz - FIOCRUZ, pelo fornecimento da cepa de Salmonella Typhimurium.

\section{REFERÊNCIAS}

BAGER, F.; PETERSEN, J. Sensitivity and specificity of different methods for the isolation of Salmonella from pigs. Acta. Vet. Scand., v.32, p.473-481, 1991.

FRESCHI, C.R.; CARVALHO, L.F.O.S.; OLIVEIRA, C.J.B. Comparison of DNAextraction methods and selective enrichment broths on the detection of Salmonella Typhimurium in swine feces by polymerase chain reaction (PCR). Braz. J. Microbiol., v.36, p.363-367, 2005.

NASCIMENTO, M.S.; BERCHIERI JR., A.; BARBOSA, M.D. et al. Comparação de meios de enriquecimento e de plaqueamento utilizados na pesquisa de Salmonella em carcaças de frango e fezes de aves. Rev. Bras. Cienc. Avic., v.2, p.85-91, 2000.
SANTOS, R.L.; ZHANG, S; TSOLIS, R.M. et al. Morphologic and molecular characterization of Salmonella Typhimurium infection in neonatal calves. Vet. Pathol., v.39, p.200-215, 2002a.

SANTOS, R.L.; TSOLIS, R.M.; BAÜMLER, A.J. et al. Hematologic and serum biochemical changes in Salmonella ser Typhimurium-infected calves. Am. J. Vet. Res., v.63, p.1145-1150, 2002b.

SILVA, D.G.; FAGLIARI, F.F.; GARCIA, T.B. Comparação da eficiência dos caldos de enriquecimento seletivo no isolamento de Salmonella dublin. Arq. Bras. Med. Vet. Zootec., v.60, p.766-768, 2008.

VELING, J.; BARKEMA, H.W.; SCHANS, I. et al. Herd-level diagnosis for Salmonella enterica subsp enterica serovar dublin infection in bovine dairy herds. Prev. Vet. Med., v.53, p.31-42, 2002.

WALTMAN, W.D. Methods for the cultural isolation of Salmonella. In: WRAY, C.; WRAY, A. Salmonella in Domestic Animals. Oxon: CABI Publishing, 2000. p.355-371.

ZAR, J.H. Biostatistical analysis. 4.ed. New Jersey: Prentice-Hall, 1999. 663p. 